\title{
Plasticity after perceptual narrowing for voice perception: reinstating the ability to discriminate monkeys by their voices at 12 months of age
}

\author{
Rayna H. Friendly ${ }^{1}$, Drew Rendall ${ }^{2}$ and Laurel J. Trainor ${ }^{1,3 *}$ \\ 1 Department of Psychology, Neuroscience and Behaviour, McMaster University, Hamilton, ON, Canada \\ ${ }^{2}$ Department of Psychology, University of Lethbridge, Lethbridge, AB, Canada \\ ${ }^{3}$ Rotman Research Institute, Baycrest Centre, Toronto, ON, Canada
}

\section{Edited by:}

Virginia Penhune, Concordia

University, Canada

\section{Reviewed by:}

Minna Huotilainen, University of Helsinki, Finland

Psyche Loui, Wesleyan University, USA

\section{${ }^{*}$ Correspondence:}

Laurel J. Trainor, Department of Psychology, Neuroscience and Behaviour, McMaster University, 1280 Main Street West, Hamilton, ON L8S 4L8, Canada

e-mail: ljt@mcmaster.ca

\begin{abstract}
Differentiating individuals by their voice is an important social skill for infants to acquire. In a previous study, we demonstrated that the ability to discriminate individuals by voice follows a pattern of perceptual narrowing (Friendly et al., 2013). Specifically, we found that the ability to discriminate between two foreign-species (rhesus monkey) voices decreased significantly between 6 and 12 months of age. Also during this period, there was a trend for the ability to discriminate human voices to increase. Here we investigate the extent to which plasticity remains at 12 months, after perceptual narrowing has occurred. We found that 12-month-olds who received 2 weeks of monkey-voice training were significantly better at discriminating between rhesus monkey voices than untrained 12-month-olds. Furthermore, discrimination was reinstated to a level slightly better than that of untrained 6-month-olds, suggesting that voice-processing abilities remain considerably plastic at the end of the first year.
\end{abstract}

Keywords: voice discrimination, perceptual narrowing, infant development, plasticity, cross-species experience, learning

\section{INTRODUCTION}

Human perception becomes specialized for socially relevant information in faces, voices, music, and language through a process of perceptual narrowing, whereby perception improves for native stimuli experienced in the environment, and becomes worse for foreign stimuli not experienced in the environment (for reviews, see Scott et al., 2007; Lewkowicz and Ghazanfar, 2009). Perceptual narrowing likely contributes to facilitating identification of individuals within one's group and becoming a fully functioning member of that group. This specialization enables people to discriminate between individuals, identify group and species members, and discern who is from one's own group and who is from outside one's group in order to help inform decisions such as whether to approach or withdraw from a situation. A number of studies indicate that, although perceptual narrowing appears to be largely accomplished by the end of the first year after birth, a certain amount of plasticity remains beyond this age. Here we examine whether around 12 months of age a relatively small amount of experience with voices from a foreign species with which infants have little prior experience can reinstate the ability to discriminate pairs of voices from that foreign species.

An advantage for processing differences in native compared to foreign stimuli by 12 months of age has been documented across a number of domains, including faces (e.g., Pascalis et al., 2002; Lewkowicz and Ghazanfar, 2006; Kelly et al., 2007; Pons etal., 2009; Simpson etal., 2010), voices (Friendly et al., 2013), music (e.g., Lynch etal., 1990; Hannon and Trehub, 2005a,b; Trainor, 2005; Trehub and Hannon, 2006; Hannon and Trainor,
2007), language (e.g., Werker and Tees, 1984; Kuhl et al., 1992, 2006; Polka and Werker, 1994; Tsao etal., 2000; Kuhl, 2004, 2008; Palmer et al., 2012; for reviews see Werker and Tees, 2005; Curtin and Werker, 2007), and even action (Loucks and Sommerville, 2012). For example, 6-month-olds are equally good at discriminating two monkey faces as they are at discriminating two human faces, but 9-month-olds and adults are much better with human faces (Pascalis et al., 2002). Similarly, in the language domain, 6-month-old infants are equally good at discriminating consonant speech sounds from two native or two foreign phonemic categories whereas 10- to 12-month-olds are much better with native categories (e.g., Werker and Tees, 1984; Kuhl et al., 2006).

Although less studied than speech and faces, voices are important social stimuli for infants. People can be identified by the unique characteristics of their voices, which is especially useful when visual cues are poor. Voices also provide cues to the listener about the size, gender, and age of a talker (e.g., Smith and Patterson, 2005). Recently, Johnson et al. (2011) found that by 7 months of age, infants exhibit an own-language effect when discriminating voices, just as they exhibit an own-race effect when discriminating faces, with better discrimination of voices speaking their native language compared to a foreign language. Subsequently, Friendly et al. (2013) found evidence of perceptual narrowing for voices toward the end of the first year after birth. Specifically, between 6 and 12 months of age, infants became significantly worse at discriminating between two foreign-species (rhesus monkey) voices, but marginally better at discriminating between two native-species (human) voices. 
The important role of experience in perceptual narrowing is indicated by research showing that sensitivity to foreign stimuli can in some cases be maintained with exposure to a foreign stimulus during the period when loss typically occurs (e.g., Burns et al., 2003; Pascalis et al., 2005; Scott and Monesson, 2009, 2010) or reinstated with exposure to a foreign stimulus after the period of loss (e.g., Kuhl et al., 2003; Hannon and Trehub, 2005b; Anzures et al., 2012). For example, Pascalis et al. (2005) found that after 2 weeks of daily exposure to monkey faces at 6 months of age, followed by 2.5 months of less frequent exposure, 9-month-olds maintained the ability to discriminate a novel set of monkey faces at a level comparable to that shown at 6 months of age. With respect to reinstatement, infants who received training at 8- to 12-months of age with other-race faces (Anzures et al., 2012), musical (Hannon and Trehub, 2005b), or linguistic (Kuhl et al., 2003) stimuli foreign to their environment, demonstrated successful processing of those stimuli, whereas their untrained counterparts did not. In the present paper, we investigate the generality of reinstatement by testing whether experience with rhesus monkey voices around 12 months of age can reverse the decrement in ability to discriminate such voices that has been documented in previous research (Friendly et al., 2013).

In designing our training protocol, we considered two features that appear to be important for exposure or training in infancy to result in learning. The first is individual-level encoding (Archambault et al., 1999; Waxman and Braun, 2005; Scott et al., 2006, 2008; Scott and Monesson, 2009, 2010). In the visual domain, Scott and Monesson (2009) repeated the Pascalis et al. (2005) monkey-face maintenance study, but used three different types of training regimen. One group of infants was trained at the individual level, similar to the infants in Pascalis et al.'s (2005) study, with parents labeling each monkey face with its own unique name (e.g., Dario, Flora, Boris, etc.). A second group of infants was trained at the category level, with parents labeling all monkey faces with the identifier "monkey." The third group of infants was trained through passive viewing alone, with no label being read by parents during exposure. Interestingly, only the infants who received individual-level training with monkey faces showed maintenance of the ability to discriminate novel monkey faces at 9 months of age. Scott and Monesson (2009) concluded that individual-level exposure was critical for obtaining the effects found in Pascalis et al.'s (2005) study because it focused infants' attention on what features were unique in each face, rather than on what the monkey faces had in common. Similarly, Anzures et al. (2012) successfully reinstated sensitivity to foreign-race faces in 8 - to 10 -month-olds after exposing them to daily videos of foreign-race women who introduced themselves by name. However, this was not compared to a no-name condition, making it unclear if labeling the faces by name influenced reinstatement in this study. Nevertheless, considering the findings from Scott and Monesson (2009), we designed our training procedure such that particular monkey voices would be associated with unique monkey names and characters.

The second feature that has been found to promote improved learning is social interaction. Kuhl etal. (2003) demonstrated that English-learning infants who were exposed to 12 sessions of Mandarin Chinese training between 9 and 10 months of age only showed a reinstatement in the ability to discriminate between Mandarin-specific phonemes at 10 to 11 months of age if they interacted with the Mandarin speakers in person. Infants who received the same training in the form of an audiovisual video or who received audio-alone training did not show a reverse in the decline of the ability to discriminate Mandarin phonemes. Similar benefits of social interaction have been found for native-language training using Baby Einstein ${ }^{\odot}$ videos, where infants required parental interaction in order to learn the words that were featured in the videos (Richert et al., 2010). Likewise, active musical interaction between infants and parents has been found to lead to earlier musical pitch enculturation compared to passive music listening (Gerry et al., 2012; Trainor et al., 2012). On the other hand, Anzures et al. (2012) found evidence of reinstatement, at 8 to 10 months of age, of sensitivity to foreign-race faces after 3 weeks of daily exposure to audio-visual videos of other-race females and Hannon and Trehub (2005b) found reinstatement of sensitivity to foreign musical rhythms in 12-month-old infants who passively listened to these rhythms at home on a $\mathrm{CD}$. However, while parents were instructed to avoid drawing the infants' attention to the music and instead to go about their regular routines, the $\mathrm{CD}$ may have been played during some type of social interaction between the parent and infant.

In the present study, we gave 11.5-month-old infants specific exposure to rhesus monkey voices under conditions that promoted individual-level encoding in the context of social interaction. In particular, we designed a storybook and accompanying audio CD narration that parents listened to with their infants twice a day for a 2-week period. The storybook contained a number of exemplars of each of four monkey characters' voices. Following this exposure, we tested infants' ability to discriminate a new set of monkey voices. We compared their discrimination of monkey voices to that of the 12- and 6-month-olds in Friendly et al. (2013) who did not receive any training. We aimed to determine whether this exposure would reinstate the ability to discriminate the monkey voices to the original level found at 6 months of age, before perceptual narrowing was fully underway.

\section{MATERIALS AND METHODS PARTICIPANTS}

Twenty-four infants (mean age $=12.0$ months, $\mathrm{SD}=0.19$ months at the time of testing; 10 females) received 2 weeks of monkeyvoice training prior to testing (Trained-12 month Group). They were compared to two groups of infants from our previous study that were tested in the identical procedure, but who did not receive any training (Friendly et al., 2013). One group was also 12 months of age $(n=24$, mean age $=12.0$ months, $\mathrm{SD}=0.19$ months; 9 females; Untrained-12 month Group) and the other group was 6 months of age $(n=24$; mean age $=6.1$ months, $\mathrm{SD}=0.22$ months, 11 females; Untrained- 6 month Group). Parents gave informed consent and reported normal hearing for all infants. Parents also reported all infants as hearing English 98-100\% of the time in their home environment. An additional 20 infants across the three groups were excluded from the final sample due to fussiness $(n=4)$, failure to pass the familiarization phase of testing (see Procedure section 2.3.2 below; 
$n=7)$, receiving less than 23 training sessions $(n=5)$, being too old at time of testing $(n=1)$ and hearing non-English languages more than $2 \%$ of time in their home environment, as reported by parents $(n=3)$.

\section{STIMULI AND APPARATUS \\ Training stimuli}

A CD-narrated picture storybook was created for the monkey voice training. Entitled "Beach Day for the Monkey Family," it contained colorful illustrations of four members of the Monkey Family going out for a day at the beach. Each monkey (labeled as Daddy, Mommy, Sister and Brother Monkey) was shown individually on a separate page, in consecutive order, six times throughout the storybook (for an example, see Figure 1). The CD-narration for the storybook was read by a monolingual English-speaking adult female and spoken in an infant-directed manner. Parents were instructed to listen to the accompanying CD and turn the page only at the sound of the chime, which occurred $4 \mathrm{~s}$ after the last vocalization on each page. The CD was designed so that every time one monkey was being viewed in the storybook, infants heard two vocalizations produced by a real rhesus macaque (Macaca mulatta). Thus, on the CD, each monkey character in the storybook was associated with the vocalizations of only one particular rhesus monkey. Twelve rhesus voice recordings were heard for each of the four rhesus monkey characters on the CD (6 tokens of the "coo" call category, heard two times each). The rhesus monkey recordings were obtained from author DR (for methodology on obtaining these recordings, see Rendall et al., 1996; Owren and Rendall, 2003), and edited using Cool Edit Pro [Syntrillium Software; sampling rate $=44.1 \mathrm{kHz}$, (intensity) resolution $=16$-bit $]$ and normalized for peak intensity across the sample. On the $\mathrm{CD}$, the recordings of each monkey were ordered randomly, with the stipulation that the same "coo" token was never presented twice in a row and that the two tokens heard on each page formed a unique pair. The four rhesus monkeys on the CD were different from the monkeys used for testing. Those on the CD formed two matched pairs (Daddy/Mommy monkey; Sister/Brother monkey) such that the set of tokens for each voice in the pair were matched for mean duration (mean $=0.367$ sessions, $\mathrm{SD}=0.065$ sessions; mean $=0.477$ sessions, $\mathrm{SD}=0.080$ sessions, for the two pairs, respectively) and minimum (mean $=218.78 \mathrm{~Hz}$, $\mathrm{SD}=116.45 \mathrm{~Hz}$; mean $=469.45 \mathrm{~Hz}, \mathrm{SD}=24.78 \mathrm{~Hz})$, maximum $($ mean $=458.48 \mathrm{~Hz}, \mathrm{SD}=70.31 \mathrm{~Hz}$; mean $=535.57 \mathrm{~Hz}$, $\mathrm{SD}=20.50 \mathrm{~Hz})$ and mean $($ mean $=340.12 \mathrm{~Hz}, \mathrm{SD}=86.48 \mathrm{~Hz}$; mean $=514.46 \mathrm{~Hz}, \mathrm{SD}=15.55 \mathrm{~Hz}$ ) F0 (analyzed using Praat software's autocorrelation algorithm, F0 searched for between 100

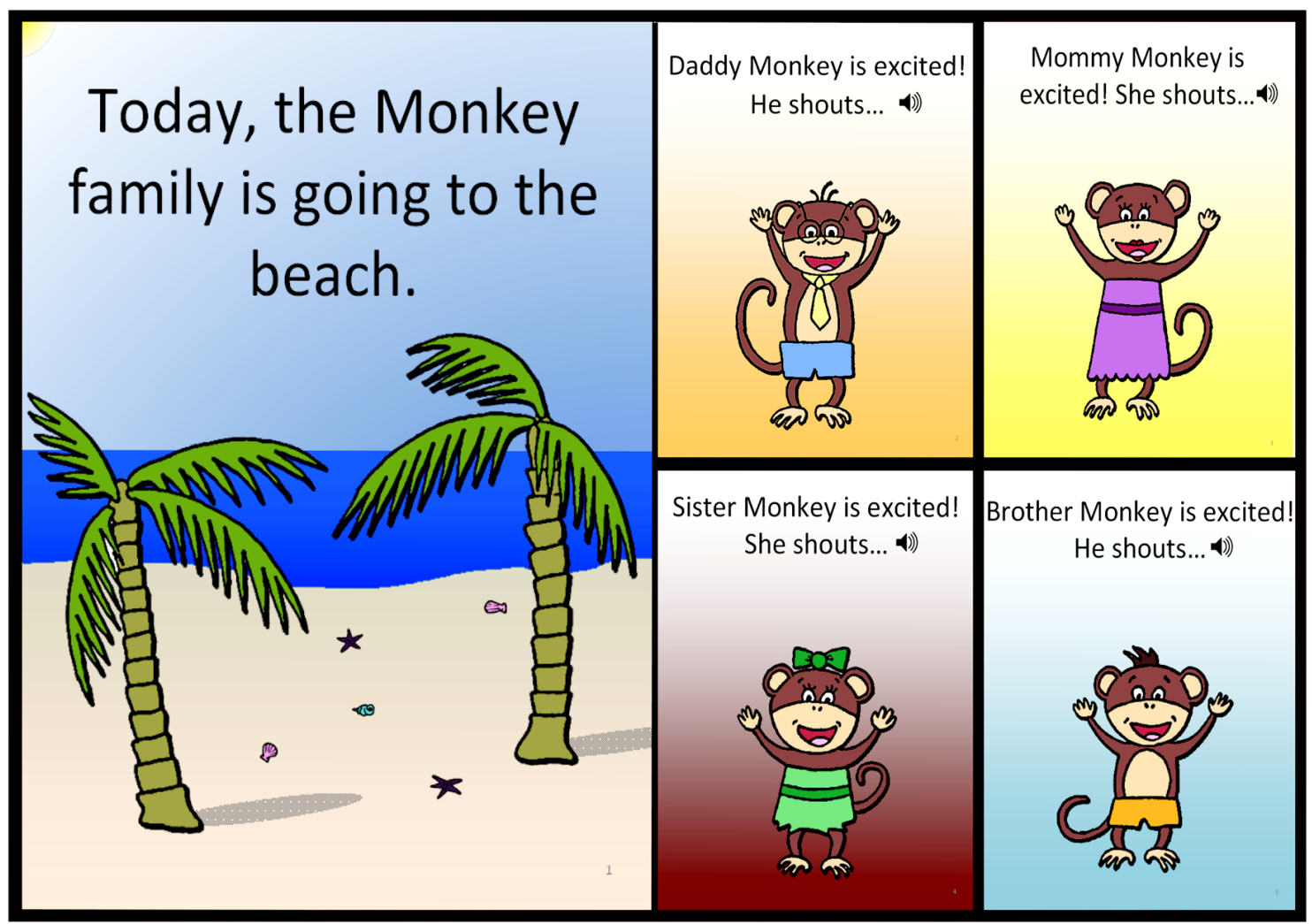

FIGURE 1 |An excerpt from the training stimulus storybook "Beach Day for the Monkey Family." A CD that contained the story narration and vocalizations belonging to four individual rhesus monkeys (six different coo tokens per monkey) accompanied the storybook. Each rhesus voice was always associated with the same monkey character in the story (either Daddy, Mommy, Sister or Brother Monkey), and the monkey characters were presented in the same order six times throughout the book. A sample of the storybook and $\mathrm{CD}$ can be found at: http://psycserv.mcmaster.ca/ ljt/RSM/RSM.html 
and $600 \mathrm{~Hz}$; Boersma and Weenink, 2009). An excerpt from the training storybook and CD (full version: $6 \mathrm{~min} 40 \mathrm{~s}$ in duration) can be found at: http://psycserv.mcmaster.ca/ljt/RSM/RSM.html.

\section{Testing stimuli}

The rhesus monkey vocalizations used for testing were identical to those used in our previous study (see Friendly et al., 2013), but different from those used during training. Six vocal samples of the "coo" call from each of four female rhesus monkeys were obtained from author DR (see Rendall et al., 1996; Owren and Rendall, 2003), edited using Cool Edit Pro [sampling rate $=44.1 \mathrm{kHz}$, (intensity) resolution $=16-\mathrm{bit}]$ and normalized for peak amplitude across the sample (Pair 1: voice 1 mean $=49 \mathrm{~dB}$, range $=46-54 \mathrm{~dB}$, voice 2 mean $=49 \mathrm{~dB}$, range $=47-51 \mathrm{~dB}$; Pair 2 : voice 1 mean $=55 \mathrm{~dB}$, range $=53-57 \mathrm{~dB}$, voice 2 mean $=56 \mathrm{~dB}$, range $=55-57 \mathrm{~dB}$ ). Two pairs of primate voices ( 6 different "coo" call tokens for each individual monkey) were paired based on acoustic analyses using Praat software, such that their sets of tokens were matched for mean duration (mean $=0.30$ sessions, $\mathrm{SD}=0.047$ sessions; mean $=0.27$ sessions, $\mathrm{SD}=0.061$ sessions, for the two pairs, respectively) and minimum (mean $=282.36 \mathrm{~Hz}$, $\mathrm{SD}=66.28 \mathrm{~Hz}$; mean $=502.48 \mathrm{~Hz}, \mathrm{SD}=18.93 \mathrm{~Hz})$, maximum $($ mean $=351.84 \mathrm{~Hz}, \mathrm{SD}=49.87 \mathrm{~Hz}$; mean $=562.59 \mathrm{~Hz}$, $\mathrm{SD}=32.49 \mathrm{~Hz})$ and mean $($ mean $=320.50 \mathrm{~Hz}, \mathrm{SD}=48.72 \mathrm{~Hz}$; mean $=542.04 \mathrm{~Hz}, \mathrm{SD}=26.30 \mathrm{~Hz}) \mathrm{F} 0$. Four conditions $(1 \mathrm{~A}$, $1 \mathrm{~B}, 2 \mathrm{~A}$ and $2 \mathrm{~B}$ ) were created for testing infants so that, for each voice pair ( 1 and 2$)$, one voice in the pair served as the "change" voice and the other as the "background" voice for condition A (see Procedure). The change and background voices were switched for condition B.

\section{PROCEDURE}

\section{Training procedure}

Two weeks prior to testing, infants in the Trained Group were mailed a package containing the illustrated storybook and accompanying $\mathrm{CD}$. The package also contained a music and language questionnaire, daily reading log and instructions for the infant's training schedule. The questionnaire asked what languages were spoken in the home and, for each, the proportion of time it was spoken, as well as whether infants attended music classes, whether parents played musical instruments, how often parents sang to their infants each week, and how often the infants listened to music each week. Parents were instructed to play the CD twice a day at home for 2 weeks, for a total of 28 training sessions, following along in the storybook with their infant. In order to ensure that the voice of each rhesus monkey on the $\mathrm{CD}$ was associated with a particular character in the book (labeled either Daddy, Mommy, Sister or Brother Monkey), parents were instructed to turn each page of the storybook only when they heard a musical chime sound. To make sure that infants were actively engaged during the monkey-voice training, parents were instructed to listen to the storybook together with their infant, interacting to engage their infant's attention as much as possible. Infants were reported to have received between 23 and 29 sessions of training (mean $=28$ sessions, approximately $6.5 \mathrm{~min}$ per session). One day after the completion of the 2-week training period, infants were brought into the lab for testing.

\section{Testing procedure}

Infants in the Trained Group were tested in the identical conditioned head turn $(\mathrm{CHT})$ procedure as infants in the Untrained Groups from Friendly et al. (2013; also see Werker et al., 1998). Infants were assigned randomly to one of 4 stimulus conditions $(1 \mathrm{~A}, 1 \mathrm{~B}, 2 \mathrm{~A}$ or $2 \mathrm{~B})$, where the $\mathrm{A}$ and $\mathrm{B}$ conditions reversed which voice of the pair was the background and which the change voice.

During the testing phase of the CHT procedure, a loudspeaker located $90^{\circ}$ to the infant's left played the six "coo" tokens from the background voice repetitively in a quasi-random order such that the same token was never repeated consecutively (stimulus onset asynchrony $=1750 \mathrm{~ms}$ ). The parent sat across from the experimenter with the infant seated on his/her lap and listened to masking music through headphones in order to eliminate potential parental influence on the infant's behaviour. The experimenter likewise listened to masking music during testing. Throughout the experiment, tokens from the background voice were played continuously. The experimenter pressed one button when the infant was paying attention and facing forward (toward the experimenter), indicating to the computer that the infant was ready for a trial. There were 24 trials. Half (12) were control (no-change) trials that were indistinguishable from the repeating background. The other half (12) were change trials, on which the background voice was replaced by one of the six tokens of the changed voice for one repetition. Across the 12 trials, each of the six changevoice tokens was presented twice in a random order. The order of change and control trials was quasi-random, with the constraint that no more than two control trials were presented in a row. The experimenter pressed a second button when the infant made a head-turn response of 45 degrees or more to the left toward the speaker from which the sounds were played. Head turn responses occurring on control trials (i.e., false alarms) were not rewarded by the computer. In contrast, head turns on change trials (i.e., hits) that occurred within $1.5 \mathrm{~s}$ of the onset of the changed voice were rewarded by the computer with $2 \mathrm{~s}$ of an animated light and toy display. The proportion of hits and false alarms were converted into d-prime $\left(\mathrm{d}^{\prime}\right)$ scores for data analysis.

Before infants began the testing phase of the CHT procedure, they first had to pass an initial training phase designed to familiarize them with the rule that when they made a headturn response to a change from one monkey's voice to another, they would be rewarded with an animated toy display. In this phase, only two of the six change-voice tokens were used and there were no control trials. Furthermore, during training the change voice was played, on average, $8 \mathrm{~dB}$ louder than the repeating background voice (see Stimuli and Apparatus) in order to make it a noticeable difference that would attract the infant's attention to look toward the loudspeaker. In order to pass the familiarization phase and proceed to the testing phase, infants were required to make four correct head-turn responses in a row within 20 training trials. Infants who did not pass this training criterion were excluded from the final data set (see Participants). Once in the testing phase, all six "coo" tokens of the change were presented without the increase in intensity used during training. 


\section{RESULTS}

Preliminary analyses revealed no significant differences in performance between male and female infants. As well, performance was not significantly related to whether or not infants attended music classes, whether parents played musical instruments, how often parents reported singing to their infants, and how often the infants were reported to listen to music. Thus these variables were not considered further in the following analyses. As can be seen in Figure 2, infants in the Trained-12 month group performed quite well at discriminating the monkey voices. Although all three groups performed significantly above chance levels (Untrained-12 month: $t(23)=3.53, p=0.002$; Untrained-6 month: $t(23)=9.70$, $p<0.001$; Trained-12 month: $t(23)=8.89, p<0.001$ ), a one-way ANOVA with group indicated a significant difference across groups in $\mathrm{d}^{\prime}$ scores, $F(2,69)=9.84, p<0.001$. A follow-up independent samples t-test indicated that infants in the Trained-12 month Group performed much better than age-matched infants in the Untrained-12 month Group, $t(46)=4.01, p<0.001$, Cohen's $d=1.16$. As well, a comparison of infants in the Trained-12 month Group to the younger infants who had not yet achieved perceptual narrowing (Untrained- 6 month Group) indicated that the trained 12-month-olds actually performed slightly better than the untrained 6-month-olds, $t(46)=2.00, p=0.05$, Cohen's $d=0.58$. Furthermore, results from our previous research on the untrained infants showed that the ability to discriminate individual monkeys by voice decreased significantly between 6 and 12 months of age (Friendly et al., 2013). Together, these findings suggest that 2 weeks of exposure to monkey voices at

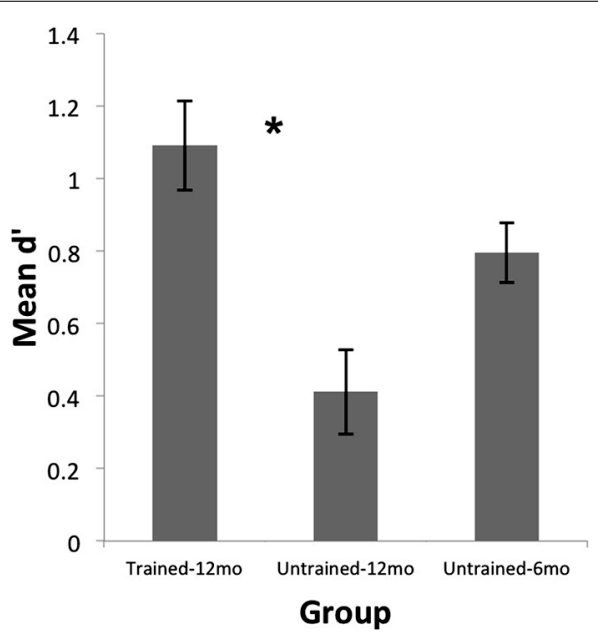

FIGURE 2 | Rhesus monkey voice discrimination abilities of 12-month-old infants $(n=24)$ who received monkey-voice training (Trained-12 month) in the present study compared to 6- (Untrained-6 month) and 12-month-old (Untrained-12 month) infants ( $n=24$ each) who did not receive training and were tested in a previous study (Friendly et al., 2013). Discrimination was much better for trained than untrained 12-month-old infants ( ${ }^{*} p<0.001$ ). Trained 12-month-olds also preformed slightly better $(p=0.05)$ than untrained 6-month-old infants, suggesting that 2 weeks of exposure to monkey voices at 12 months reinstates processing of foreign-species voices to a level observed at 6 months, or better, before perceptual narrowing is fully underway. Error bars represent SEM
11.5-12 months of age (after perceptual narrowing has occurred) can reinstate sensitivity to voices from a foreign species to a level equivalent to or better than that observed at 6 months of age.

\section{DISCUSSION}

In previous work, we showed that the development of specialization for own-species voice discrimination follows a pattern of perceptual narrowing, with a decrease in infants' ability to individuate rhesus monkey voices between 6 and 12 months of age (Friendly etal., 2013). In the present paper, we found that after 2 weeks of twice-daily exposure to rhesus monkey voices in the form of a CD-narrated storybook, 12-month-old infants demonstrated significantly better discrimination of novel rhesus monkey voices not heard during training compared to 12-monthold infants who received no such training. Furthermore, the performance of the 12-month-olds who received exposure to the monkey voices was actually slightly better than that of untrained 6month-old infants. The fact that monkey voice exposure enhanced discrimination of monkey voices in 12-month-olds to a level seen in 6-month-old infants indicates that the processes underlying perceptual narrowing for voice identification retain considerable plasticity at least until 12 months of age. This conclusion is consistent with studies in other domains that indicate that exposure to a socially relevant foreign stimulus can either maintain (Burns et al., 2003; Pascalis et al., 2005; Scott and Monesson, 2009, 2010) or reinstate (Kuhl et al., 2003; Hannon and Trehub, 2005b; Anzures et al., 2012) sensitivity past the period during which perceptual narrowing normally occurs.

Previous studies on face processing suggest that maintenance of sensitivity for individuating faces from a foreign species requires that the exposure to those faces be at an individual level, with different labels, such as names, being applied to the different faces in the exposure set (e.g., Scott et al., 2006; Scott and Monesson, 2009). These studies found that having infants simply observe foreign-species faces, or experience them in the context of a common label applied to all faces (e.g., "monkey"), does not lead to maintenance of the ability to discriminate these faces. As well, Anzures et al. (2012) found that exposure to labeled foreign-race faces at 8 - to 10 -months reinstates infants' ability to recognize foreign-race faces, although they did not test under conditions with no labeling. Scott and Monesson (2009) suggest that labeling faces by name might draw infants' attention to the differences between individuals, rather than to what the individuals have in common. On the other hand, phoneme categories in speech and metrical structures in music do not apply to individual people or individuals from other species (although changes in phonemes can signal changes in word meaning), and explicit individuation though the use of labels in these cases does not seem to be necessary for exposure to foreign categories or structures to disrupt perceptual narrowing (Kuhl et al., 2003; Hannon and Trehub, 2005b). The case of distinguishing individuals by their voice would seem to be similar to the case of distinguishing individuals by their face, suggesting that attention to differences between individuals during exposure might be critical for reinstating sensitivity to voices from a foreign species. This could be tested in future research with respect to distinguishing voices by using a 
training protocol that either applies no label at all or that applies the label "monkey" to each rhesus monkey voice sample during training.

Social interaction has also been identified as important for plasticity during the period of perceptual narrowing (Kuhl et al., 2003; Gerry et al., 2012). For example, Kuhl et al. (2003) found that interpersonal interaction between English-learning infants and Mandarin-speaking adults reinstated infant's sensitivity to Mandarin phonemic distinctions after narrowing had occurred, whereas exposure to audio-visual and audio-alone recordings of these adults speaking Mandarin did not. On the other hand, Hannon and Trehub (2005b) found that 2 weeks of twice-daily passive exposure to foreign musical rhythms was sufficient to reinstate 12-month-olds' ability to detect violations in foreign rhythmic structure. In the present study, infants receive training in the social context of parental interaction. It is possible that passive exposure to foreign stimuli can affect perceptual narrowing, but that exposure in a social context is more powerful. It remains for future research to determine whether the social interaction during the training phase of the present study was a necessary condition for the reinstatement of sensitivity to monkey voices. In order to investigate this, future studies could test training conditions in which parents are instructed to avoid interaction with their infant while experiencing the audiobook (audio-visual condition) or instructed to listen to the narration without looking at the storybook (audio-alone condition). If social interaction is as important for plasticity during perceptual narrowing for voices as it is for phonemic categories, then the infants in the audio-visual and audio-alone conditions should show no (or less) reinstatement of ability to discriminate monkey voices compared to the trained 12-month-olds in the present study.

In interpreting the effects of different kinds of experience on reinstatement of abilities at 12 month of age, it is important to consider the results from a study by Fair et al. (2012), in which sensitivity to distinctions in foreign-species (monkey) faces at 12 months was observed without a prescribed at-home training period, by simply by extending the length of the familiarization period at the time of testing. Specifically, Fair et al. (2012) demonstrated that 12-month-olds showed no evidence of discriminating unfamiliar monkey faces after $20 \mathrm{~s}$ of familiarization, but did discriminate them after $40 \mathrm{~s}$ of familiarization. This extended familiarization period could be considered a relatively brief form of training, but it is surprising that reinstatement could be achieved after such a brief training.

A final question concerns the age range over which the window of plasticity remains open with respect to learning to discriminate foreign voices. In other domains, there is evidence that some plasticity remains throughout the lifespan in that exposure to foreign stimuli in childhood (e.g., Feinman and Entwisle, 1976; Cheour et al., 2002; Shestakova et al., 2003; Wang and Kuhl, 2003;

\section{REFERENCES}

Anzures, G., Wheeler, A., Quinn, P. C., Pascalis, O., Slater, A. M., Heron-Delaney, M., et al. (2012). Brief daily exposures to Asian females reverses perceptual narrowing for Asian faces in Caucasian infants. $J$.
Exp. Child Psychol. 112, 484-495. doi:

Archambault, A., O'Donnell, C., and Schyns, P. G. (1999). Blind to object changes: when learning the same object at different levels of categorization modifies its perception. Psychol. 10.1016/j.jecp.2012.04.005

Sangrigoli et al., 2005; Macchi Cassia et al., 2009) or adulthood (e.g., Tees and Werker, 1984; Bradlow et al., 1999; McCandliss etal., 2002; Iverson et al., 2005; Pruitt etal., 2006; Scott et al., 2006, 2008; de Heering and Rossion, 2008; Kuefner et al., 2008; Zhang et al., 2009) results in improved processing of those stimuli, particularly if the training contains highly variable and numerous stimuli (Zhang et al., 2009), if differences between the stimuli are exaggerated (McCandliss et al., 2002), and if the person had some exposure to the stimuli earlier in life (e.g., Lenneberg, 1967; Tees and Werker, 1984; Newport et al., 2001; Sangrigoli et al., 2005; Macchi Cassia et al., 2009; Oh et al., 2010). However, completely native-like processing of foreign stimuli appears to be very difficult, if not impossible, to achieve in adulthood (e.g., Takagi and Mann, 1995; Flege et al., 1999; McCandliss et al., 2002; Takagi, 2002; Hannon and Trehub, 2005b; Iverson et al., 2005, for reviews see Birdsong, 2006; Hernandez and Li, 2007). Nevertheless, Sangrigoli et al. (2005) found native-like discrimination of Caucasian (French) faces by Korean adults who were adopted by French families between 3 and 9 years of age, suggesting that it is possible to demonstrate native levels of foreign-race face processing under certain conditions. In the present study, informal feedback from parents who participated with their infants suggests that parents had a difficult time distinguishing between the four monkey voices used in the storybook, even after listening to the story with their infant for the 2-week, twice-daily period. However, it is possible that with sufficient training adults could become proficient at discriminating foreign voices, as their ability to discriminate the monkey voices is poor, but above chance levels, without training. Again, this could be investigated in a future study.

In summary, perceptual narrowing achieved by the end of the first year after birth for discriminating voices can be modified by 2 weeks of exposure to voices from a foreign species, indicating a period of flexibility and plasticity following narrowing. It remains for future research to determine, (1) the time course of this plasticity across the lifespan, (2) effects of the social context, (3) whether individual-level training is important in perceptual narrowing for voice discrimination, (4) whether perceptual narrowing also occurs for other voice types (e.g., vocalizations from other species, sexes, races, and age groups), and (5) which particular acoustic characteristics of native and/or foreign voices, if any, promote the perceptual narrowing for voices observed in Friendly et al. (2013) and the reinstatement of foreign-voice discrimination in the present study.

\section{ACKNOWLEDGMENTS}

This research was supported by a grant to Laurel J. Trainor from the Natural Sciences and Engineering Research Council of Canada. We thank Ren Ee Choo, Aliyah Mohamed and Andrea Unrau for assistance in data collection.

Sci. 10, 249-255. doi: 10.1111/14679280.00145

Birdsong, D. (2006). Age and second language acquisition and processing: a selective overview. Lang. Lear. 56, 9-49. doi: 10.1111/j.1467-9922. 2006.00353.x
Boersma, P., and Weenink, D. (2009). Praat: Doing Phonetics by Computer Version 5.1.04. Computer program. Available at: http://www.praat. org/

Bradlow, A. R., Akahane-Yamada, R., Pisoni, D. B., and Tohkura, Y. 
(1999). Training Japanese listeners to identify English /r/and/l/: longterm retention of learning in speech perception and production. Percept. Psychophys. 61, 977-985. doi: 10.3758/BF03206911

Burns, T. C., Werker, J. F., and McVie, K. (2003). "Development of phonetic categories in infants raised in bilingual and monolingual environments," in Proceedings of the 27th Annual Boston University Conference of Language Development, eds B. Beachley, A. Brown, and F. Conlin (Sommerville, MA: Cascadilla Press), 173-184.

Cheour, M., Shestakova, A., Alku, P., Ceponiene, R., and Näätänen, R. (2002). Mismatch negativity shows that 3-6-year-old children can learn to discriminate non-native speech sounds within two months. Neurosci. Lett. 325, 187-190. doi: 10.1016/ S0304-3940(02)00269-0

Curtin, S., and Werker, J. F. (2007). “The perceptual foundations of phonological development," in The Oxford Handbook of Psycholinguistics, ed. M. G. Gaskell (Oxford, UK: Oxford University Press), 579-600.

de Heering, A., and Rossion, B. (2008). Prolonged visual experience in adulthood modulate holistic face perception. PLoS ONE 3:e2317. doi: 10.1371/journal.pone. 0002317

Fair, J., Flom, R., Jones, J., and Martin, J. (2012). Perceptual learning: 12-month-olds' discrimination of monkey faces. Child Dev. 83, 1996-2006. doi: 10.1111/j.14678624.2012.01814.x

Feinman, S., and Entwisle, D. R. (1976) Children's ability to recognize other children's faces. Child Dev. 47, 506510. doi: 10.2307/1128809

Flege, J. E., Yeni-Komshian, G. H., and Liu, S. (1999). Age constraints on second-language acquisition. J. Mem. Lang. 41, 78-104. doi: 10.1006/jmla. 1999.2638

Friendly, R. H., Rendall, D., and Trainor, L. J. (2013). Learning to differentiate individuals by their voices: infants' individuation of native- and foreign-species voices. Dev. Psychobiol. (in press). doi: 10.1002/dev. 21164

Gerry, D., Unrau, A., and Trainor, L. J. (2012). Active music classes in infancy enhance musical, communicative and social development. Dev. Sci. 15, 398-407. doi: 10.1111/j.14677687.2012.01142.x

Hannon, E. E., and Trainor, L. J. (2007). Music acquisition: effects of enculturation and formal training on development. Trends Cogn. Sci.
11, 466-472. doi: 10.1016/j.tics. 2007.08.008

Hannon, E. E., and Trehub, S. E. (2005a). Metrical categories in infancy and adulthood. Psychol. Sci. 16, 48-55. doi: 10.1111/j.09567976.2005.00779.x

Hannon, E. E., and Trehub, S. E. (2005b). Tuning in to musical rhythms: infants learn more readily than adults. Proc. Natl. Acad. Sci. U.S.A. 102, 12639-12643. doi: 10.1073/pnas.0504254102

Hernandez, A., and Li, P. (2007). Age of acquisition: its neural and computational mechanisms. Psychol. Bull. 133, 638-650. doi: 10.1037/00332909.133.4.638

Iverson, P., Hazan, V., and Bannister, K. (2005). Phonetic training with acoustic cue manipulations: a comparison of methods for teaching English /r/-/l/ to Japanese adults. J. Acoust. Soc. Am. 118, 3267-3278. doi: 10.1121/1.2062307

Johnson, E. K., Westrek, E., Nazzi, T. and Cutler, A. (2011). Infant ability to tell voices apart rests on language experience. Dev. Sci. 14, 10021011. doi: 10.1111/j.1467-7687.2011. 01052.x

Kelly, D. J., Quinn, P. C., Slater, A. M., Lee, K., Ge, L., and Pascalis, O. (2007). The other-race effect develops during infancy. Psychol. Sci. 18, 1084-1089. doi: 10.1111/j.14679280.2007.02029.x

Kuefner, D., Macchi Cassia, V., Picozzi, M., and Bricolo, E. (2008). Do all kids look alike? Evidence for an other-age effect in adults. J. Exp. Psychol. Hum. Percept. Perform. 34, 811-817. doi: 10.1037/0096-1523.34.4.811

Kuhl, P. K. (2004). Early language acquisition: cracking the speech code. Nat. Rev. Neurosci. 5, 831-843. doi: 10.1038/nrn1533

Kuhl, P. K. (2008). "Linking infant speech perception to language acquisition: phonetic learning predicts language growth," in Infant Pathways to Language: Methods, Models, and Research directions, eds P. McCardle, J. Colombo, and L. Freund (New York: Erlbaum), 213-243.

Kuhl, P. K., Stevens, E., Hayashi, A., Deguchi, T., Kiritani, S., and Iverson, P. (2006). Infants show a facilitation effect for native language phonetic perception between 6 and 12 months. Dev. Sci. 9, F13F21. doi: 10.1111/j.1467-7687.2006. 00468.x

Kuhl, P. K., Tsao, F. M., and Liu, H. M. (2003). Foreign language experience in infancy: effects of short-term exposure and social interaction on phonetic learning.
Proc. Natl. Acad. Sci. U.S.A. 100, 9096-9101. doi: 10.1073/pnas. 1532872100

Kuhl, P. K., Williams, K. A., Lacerda, F., Stevens, K. N., and Lindblom, B. (1992). Linguistic experience alters phonetic perception in infants by 6 months of age. Science 255, 606-608. doi: $10.1126 /$ science. 1736364

Lenneberg, E. H. (1967). Biological Foundations of Language. New York: John Wiley \& Sons, Inc.

Lewkowicz, D. J., and Ghazanfar, A. A. (2006). The decline of cross-species intersensory perception in human infants. Proc. Natl. Acad. Sci. U.S.A. 103, 6771-6774. doi: 10.1073/pnas. 0602027103

Lewkowicz, D. J., and Ghazanfar, A. A. (2009). The emergence of multisensory systems through perceptual narrowing. Trends Cogn. Sci. 13, 470478. doi: 10.1016/j.tics.2009.08.004

Loucks, J., and Sommerville, J. A. (2012). Developmental changes in the discrimination of dynamic human actions in infancy. Dev. Sci. 15, 123-130. doi: 10.1111/j.14677687.2011.01099.x

Lynch, M. P., Eilers, R. E., Oller, D. K., and Urbano, R. C. (1990). Innateness, experience, and music perception. Psychol. Sci. 1, 272-276. doi: 10.1111/j.1467-9280.1990.tb00213.x

Macchi Cassia, V., Kuefner, D., Picozzi M., and Vescovo, E. (2009). Early experience predicts later plasticity for face processing: evidence for the reactivation of dormant effects. Psychol. Sci. 20, 853-859. doi: 10.1111/j.14679280.2009.02376.x

McCandliss, B. D., Fiez, J. A., Protopapas, A., Conway, M., and McClelland, J. L. (2002). Success and failure in teaching the $[\mathrm{r}]-[\mathrm{l}]$ contrast to Japanese adults: tests of a Hebbian model of plasticity and stabilization in spoken language perception. Cogn. Affect. Behav. Neurosci. 2, 89-108. doi: 10.3758/CABN.2.2.89

Newport, E. L., Bavelier, D., and Neville, H. J. (2001). "Critical thinking about critical periods: perspectives on a critical period for language acquisition, in Language, Brain and Cognitive Development: Essays in Honor of Acques Mehler, ed. E. Doupoux (Cambridge, MA: MIT Press), 481-502.

Oh, J. S., Au, T. K. F., and Jun, S. A. (2010). Early childhood language memory in the speech of international adoptees. J. Child Lang. 37, 1123-1132. doi: 10.1017/ S0305000909990286

Owren, M. J., and Rendall, D. (2003). Salience of caller identity in rhesus monkey (macac mulatta) coos and screams: perceptual experiments with human (homo sapiens) listeners. J. Comp. Psychol. 117, 380-390. doi: 10.1037/0735-7036.117.4.380

Palmer, S. B., Fais, L., Golinkoff, R. M., and Werker, J. F. (2012). Perceptual narrowing of linguistic sign occurs in the 1st year of life. Child Dev. 83, 543-553. doi: 10.1111/j.14678624.2011.01715.x

Pascalis, O., de Haan, M., and Nelson, C. A. (2002). Is face processing species-specific during the first year of life? Science 296, 1321-1323. doi: 10.1126/science.1070223

Pascalis, O., Scott, L. S., Kelly, D. J., Shannon, R. W., Nicholson, E., Coleman, M., et al. (2005). Plasticity of face processing in infancy. Proc. Natl. Acad. Sci. U.S.A. 102, 5297-5300. doi: 10.1073/pnas.0406627102

Polka, L., and Werker, J. F. (1994). Developmental changes in perception of nonnative vowel contrasts. $J$. Exp. Psychol. Hum. Percept. Perform. 20, 421-435. doi: 10.1037/00961523.20.2.421

Pons, F., Lewkowicz, D. J., Soto-Faraco, S., and Sebastián-Gallés, N. (2009). Narrowing of intersensory speech perception in infancy. Proc. Natl. Acad. Sci. U.S.A. 106, 10598-10602. doi: 10.1073/pnas.0904134106

Pruitt, J. S., Jenkins, J. J., and Strange, W. (2006). Training the perception of Hindi dental and retroflex stops by native speakers of American English and Japanese. J. Acoust. Soc. Am. 119, 1684-1696. doi: 10.1121/1.2161427

Rendall, D., Rodman, P. S., and Emond, R. E. (1996). Vocal recognition of individuals and kin in free-ranging rhesus monkeys. Anim. Behav. 51, 1007-1015. doi: 10.1006/anbe. 1996.0103

Richert, R. A., Robb, M. B., Fender, J. G., and Wartella, E. (2010). Word learning from baby videos. Arch. Pediatr. Adolesc. Med. 164, E1-E5. doi: 10.1001/archpediatrics.2010.24

Sangrigoli, S., Pallier, C., Argenti, A., Ventureyra, V. A. G., and de Schonen, S. (2005). Reversibility of the otherrace effect in face recognition during childhood. Psychol. Sci. 16, 440-444.

Scott, L. S., and Monesson, A. (2009). The origins of biases in face perception. Psychol. Sci. 20, 676-680. doi: 10.1111/j.1467-9280.2009.02348.x

Scott, L. S., and Monesson, A. (2010). Experience-dependent neural specialization during infancy. Neuropsychologia 48, 1857-1861. doi: 10.1016/ j.neuropsychologia.2010.02.008

Scott, L. S., Pascalis, O., and Nelson, C. A. (2007). A domain-general theory of the development of perceptual discrimination. Curr. Direct. Psychol. 
Sci. 16, 197-201. doi: 10.1111/j.14678721.2007.00503.x

Scott, L. S., Tanaka, J. W., Sheinberg, D. L., and Curran, T. (2006). A reevaluation of the electrophysiological correlates of expert object processing. $J$. Cogn. Neurosci. 18, 1453-1465. doi: 10.1162/jocn.2006.18.9.1453

Scott, L. S., Tanaka, J. W., Sheinberg, D. L., and Curran, T. (2008). The role of category learning in the acquisition and retention of perceptual expertise: behavioral and neurophysiological study. Brain Res. 1210, 204-215. doi: 10.1016/j.brainres.2008.02.054

Shestakova, A., Huotilainen, M., Ėeponiene, R., and Cheour, M. (2003). Event-related potentials associated with second language learning in children. Clin. Neurophysiol. 114, 1507-1512. doi: 10.1016/S13882457(03)00134-2

Simpson, E. A., Varga, K., Frick, J. E., and Fragaszy, D. (2010). Infants experience perceptual narrowing for nonprimate faces. Infancy 16, 318-328. doi: 10.1111/j.1532-7078. 2010.00052.x

Smith, D. R., and Patterson, R. D. (2005). The interaction of glottalpulse rate and vocal-tract length in judgments of speaker size, sex, and age. J. Acoust. Soc. Am. 118, 3177 3186. doi: 10.1121/1.2047107

Takagi, N. (2002). The limits of training Japanese listeners to identify English/r/and/1/: eight case studies. J. Acoust. Soc. Am. 111, 2887-2896. doi: $10.1121 / 1.1480418$
Takagi, N., and Mann, V. A. (1995). The limits of extended naturalistic exposure on the perceptual mastery of English /r/ and /l/ by adult Japanese learners of English. Appl. Psycholinguist. 16, 379-405.

Tees, R. C., and Werker, J. F. (1984) Perpetual flexibility: maintenance or recovery of the ability to discriminate non-native speech sounds. Can. J. Psychol. 34, 579-590. doi: 10.1037/h0080868

Trainor, L. J. (2005). Are there critical periods for music development? Dev. Psychobiol. 46, 262-278. doi: 10.1002/dev.20059

Trainor, L. J., Marie, C., Gerry, D., Whiskin, E., and Unrau, A. (2012). Becoming musically enculturated: effects of music classes for infants on brain and behavior. Ann. N. Y. Acad. Sci. 1252, 129 138. doi: $10.1111 /$ j.1749-6632.2012. 06462.x

Trehub, S. E., and Hannon, E. E. (2006). Infant music perception: domaingeneral or domain-specific mechanisms? Cognition 100, 73-99. doi: 10.1016/j.cognition.2005.11.006

Tsao, F., Liu, H., Kuhl, P. K., and Tseng, C. (2000). "Perceptual discrimination of a Mandarin fricative-affricate contrast by English-learning and Mandarin-learning infants," Poster Presented at the Meeting of the International Society on Infant Studies, Brighton, England.

Wang, Y., and Kuhl, P. K. (2003). "Evaluating the "critical period" hypothesis: perceptual learning of Mandarin tones in American adults and American children at 6,10 and 14 years of age," Poster Presented at the 15th International Congress of Phonetic Sciences, Barcelona, 15371540.

Waxman, S. R., and Braun, I. E. (2005). Consistent (but not variable) names as invitations to form object categories: new evidence from 12-month-old infants. Cognition 95, B59-B68. doi: 10.1016/j.cognition. 2004.09.003

Werker, J. F., Shi, R., Desed. jardins, R., Pegg, J. E., Polka, L., and Patterson, M. (1998). "Three methods for testing infant speech perception," in Perceptual Development: Visual, Auditory, and Speech Perception in Infancy, ed. A. M. Slater (London: UCL Press), 389-420.

Werker, J. F., and Tees, R. C. (1984). Cross-language speech perception: evidence for perceptual reorganization during the first year of life. Infant Behav. Dev. 79, 4963. doi: 10.1016/S0163-6383(84) 80022-3

Werker, J. F., and Tees, R. C. (2005). Speech perception as a window for understanding plasticity and commitment in language systems of the brain. Dev. Psychobiol. 46, 233-251. doi: 10.1002/dev. 20060

Zhang, Y., Kuhl, P. K., Imada, T. Iverson, P., Pruitt, J., Stevens, E. B., etal. (2009). Neural signatures of phonetic learning in adulthood: a magnetoencephalography study. Neuroimage 46, 226-240. doi: $\quad 10.1016 /$ j.neuroimage.2009. 01.028

Conflict of Interest Statement: The authors declare that the research was conducted in the absence of any commercial or financial relationships that could be construed as a potential conflict of interest.

Received: 29 April 2013; accepted: 18 September 2013; published online: 09 October 2013.

Citation: Friendly RH, Rendall D and Trainor LJ (2013) Plasticity after perceptual narrowing for voice perception: reinstating the ability to discriminate monkeys by their voices at 12 months of age. Front. Psychol. 4:718. doi: 10.3389/ fpsyg.2013.00718

This article was submitted to Auditory Cognitive Neuroscience, a section of the journal Frontiers in Psychology. Copyright (C) 2013 Friendly, Rendall and Trainor. This is an open-access article distributed under the terms of the Creative Commons Attribution License (CC BY). The use, distribution or reproduction in other forums is permitted, provided the original author(s) or licensor are credited and that the original publication in this journal is cited, in accordance with accepted academic practice. No use, distribution or reproduction is permitted which does not comply with these terms. 